\title{
A LIQUID WATER MANAGEMENT STRATEGY FOR PEM FUEL CELL STACKS
}

By

\author{
Trung Van Nguyen ${ }^{*}$ \\ Chemical \& Petroleum Engineering Department \\ The University of Kansas \\ Lawrence, KS 66045 \\ and \\ Mack W. Knobbe \\ TVN Systems, Inc. \\ Lawrence, KS 66046
}

\author{
Submitted as \\ A Research Paper \\ To \\ Dr. C. K. Dyer \\ The Journal of Power Sources \\ 16 Seven Oaks Circle \\ Madison, New Jersey 07940-1314 \\ USA
}

$1^{\text {st }}$ submission: September 18, 2002

Key words: PEM Fuel Cells, Water Management, Electrode Flooding, Sequential Exhausting

\footnotetext{
* Author to whom correspondence should be addressed.
} 


\begin{abstract}
Gas and water management are key to achieving good performance from a PEM fuel cell stack. Previous experimentation had found, and this experimentation confirms, that one very effective method of achieving proper gas and water management is the use of an Interdigitated flow field design. However, the results of a single fuel cell with an Interdigitated flow field could not be extended to a multi-cell stack because of the inability to establish uniform gas flow to each individual cell. Since the interdigitated flow field uses the flow of gas for excess water removal, a deficient flow of gas causes the cell to become flooded. To alleviate this problem of unequal gas distribution, a method of sequentially exhausting each individual cell was developed. This method controls each cell's exhaust so that only one cell at any given time has an open exhaust port, thereby ensuring gas will flow through that cell. By sequentially exhausting each cell, it will be ensured that the gas will flow to each cell and provide the water management necessary to achieve good performance. This was demonstrated in a three-cell PEM stack with interdigitated flow fields operating at ambient pressure and temperature on neat hydrogen and oxygen. The results showed that the use of sequential exhaust control improved the peak power from $0.26 \mathrm{~W} / \mathrm{cm}^{2} /$ cell without exhaust control to $0.50 \mathrm{~W} / \mathrm{cm}^{2} /$ cell, a doubling of the power density.
\end{abstract}




\section{INTRODUCTION}

Energy is an essential driving force for modern society. In particular, electricity has become the standard source of power for almost every aspect of life. Electric power runs our lights, our televisions, our cell phones, our laptops, etc. However, it has become apparent that the current methods of producing this most valuable commodity, combustion of fossil fuels, are of limited supply and has become detrimental for the earth's environment. It is also self evident, given the fact that these resources are non-renewable, that these sources of energy will eventually run out. The depletion of the earth's energy reserves will only accelerate given the ever-increasing population. For these reasons, much effort is now being placed on eliminating the use of combustion of non-renewable fossil fuels as a source of power. One of the most promising alternatives to the burning of fossil fuel in the production of electric power is the Proton Exchange Membrane (PEM) Fuel Cell.

The PEM fuel cell has many advantages to the current internal combustion engine. Since it is not limited by the Carnot cycle, it can achieve much higher efficiencies than a combustion cycle [1]. The PEM fuel cell is also environmentally friendly. When operated on hydrogen, the PEM fuel cell is a zero emission power source. Even when operated on reformate hydrogen (hydrogen evolved from hydrocarbon fuel sources) the emissions are lower than in a standard combustion engine. Other advantages of this fuel cell system include the simplicity of design, low noise operation and economic independence. It will help developing countries that lack the power grid infrastructure by using fuel cells for localized electric power stations. Fuel cells can eliminate the need for large, noisy power plant hundreds of miles from the eventually usage location. Furthermore, by localizing power generation the power loss due to transmission through long distance power lines is eliminated. 
A PEM fuel cell consists of a proton-conductive solid polymer electrolyte sandwiched between two porous electrodes loaded with platinum catalysts to promote the electron-generating hydrogen oxidation reaction and the electron-consuming oxygen reduction reaction. On top of these electrodes are the porous gas diffusion layers (GDLs) and the gas distributor plates. The GDLs are used to provide gas access to the region directly above the shoulders of the flow field on the distributor plates. The gas distributor plates provide electric current collection, reactant gas distribution and product (gas and liquid) removal to and from the electrodes. See schematic in Figure 1 for details.

In order to achieve good performance, several parameters in a fuel cell must be optimized. A good fuel cell must provide optimal 1) electronic conduction from the anode and cathode catalyst sites to the current collectors, 2) ionic conduction from the anode catalyst sites to the catalyst sites, 3) reactant gas access to the catalyst sites from the channels for both the anode and cathode, and 4) gaseous and liquid product removal from the catalyst sites. All these issues have been addressed at the single-cell level with recent developments in membrane, electrodes, and membrane and electrode assembly [2]. However, addressing these issues at the fuel-cell-stack level requires an understanding that has not been adequately discussed in the public literature. For practical applications fuel cells are connected electrically in series to create a fuel cell stack with a higher voltage. However, fuel cells in a fuel cell stack are often designed to feed from a common fuel or oxidant feed stream and exhaust to a common fuel or oxidant exhaust stream as shown in Figure 2 to keep the total gas pressure drop across the fuel cell stack low. In other words, in terms of electrical connection fuel cells are connected in series, but in terms of fluid distribution fuel cells are connected in parallel. 
This arrangement, however, creates a major problem. Since a common feed stream is used to supply gas to all cells, it is difficult to guarantee that all cells will receive the same gas flow rate. Furthermore, due to non-uniform temperature distribution in a fuel cell stack during operation non-uniform liquid water distribution is created in the electrodes and flow channels. Since liquid water is a more viscous fluid, its non-uniform existence in a fuel cell stack leads to non-uniform, cell-to-cell gas distribution in a fuel cell stack. This problem is self-defeating. Once a cell has water built up, less gas will flow to that cell. Once less gas flows to that cell, less water is removed and the problem escalates, resulting in reactant-starved condition. This liquid water management problem becomes more severe when direct liquid water injection is used to humidify the anode gas stream [3]. Reactant-starved condition is of great concern to fuel cell users because a starved cell could lead to cell reversal. Cell reversal, which is often reflected by a negative cell potential, is a condition in which a hydrogen-starved anode is forced by the current from other cells in a fuel cell stack to oxidize water to generate oxygen and an oxygenstarved electrode is forced to reduce protons to hydrogen. The presence of oxygen in a hydrogen electrode and hydrogen in an oxygen electrode could result local hot spots in the membrane and electrode assembly leading to failure of the fuel cells and ultimately to potential catastrophic conditions in a fuel cell stack. The approach often employed by fuel cell stack developers to ensure adequate gas flow to all cells is to use high stoichiometric gas flow rates and flow field designs with high-pressure drops to prevent one cell or a group of cells from receiving most of the gas flow while other cells becoming reactant starved during operation [4]. Serial gas connection, which is often used for fuel cell stacks consisting of a few cells, can also be used to prevent non-uniform gas distribution [5]. In the serial configuration the gas from the outlet of the first cell is fed to the inlet of the second cell and so on until the last cell. To ensure that each 
cell receives adequate fuel and oxidant and to prevent reactant-starved condition in a fuel cell stack, a more active method of gas and liquid management is required. This work discusses the use of the sequential exhaust or purging of individual cells as a reactant gas and liquid water management strategy and presents the results from a multiple fuel cell stack obtained using this approach.

The concept of this reactant gas and liquid water management is to control the exhaust. A device is used to allow each individual cell in the stack to exhaust separately from the other cells in the stack [4,6]. More specifically, only one cell at a time is allowed to exhaust, thereby insuring that that cell is receiving gas flow. This insures that no cell will be starved of fuel. Another advantage to this method of exhaust control is the reduction in equivalent stoichiometry. In standard operation, excess gas is flown through the cell to ensure the water is being flushed out and to ensure that high reactant concentrations are maintained. This excess is essentially wasted fuel and energy to drive the blower or compressor used to supply air to the fuel cell stack. With sequential exhausting, the momentary gas flow rate is much higher, so there is more water removal by shear force. Also, there is a result of lower stoichiometric flow rate. Since the cell is essentially dead-ended when not being purged, it is operating on exactly one stoichiometric flow rate. The only waste gas is seen in the purge cycle, which averages out over time to be much less than with equivalent conventional operation. Therefore, the use of sequential exhaust purge will achieve higher stack power densities with less wasted fuel. By achieving higher power density, another step toward commercial viability will be achieved. 


\section{EXPERIMENTAL}

For all experiments within, the gas distributor plates were made of carbon and an interdigitated flow field design was used for all cells [3,7]. The gas channels were machined inhouse using a computerized milling machine. Side exhausts were machined so that each cell could exhaust independently from the others. The plates used were $7 \mathrm{x} 7 \mathrm{~cm}$ square plates with a thickness of $0.5 \mathrm{~cm}$. The gas diffusion layer used was carbon cloth, with a thickness of 250 microns, purchased from E-Tek, Inc. The MEAs used were purchased from W.L. Gore and Associates. The membranes used in the MEAs were 25 microns thick. The active catalyst area was $9 \mathrm{~cm}^{2}(3 \mathrm{~cm} \times 3 \mathrm{~cm})$. The catalyst loading was $0.4 \mathrm{mg} \mathrm{Pt} / \mathrm{cm}^{2}$. The fuel cells were assembled into a three-cell arrangement where one input manifold was used to feed hydrogen to all the anode compartments and another to feed oxygen to all the cathodes. Each cell compartment has its own side exhaust that is connected to an electromechanical valve. Exhaust from the valves was vented directly into the hood. In practice, the exhaust from the valves could be connected to a common stack outlet.

Two devices were made to control the sequential exhausting [6]. The first device made was a simple rotating manifold distributor. This was made of ultra-high molecular weight polyethylene. The exhausts from the cell were connected to a distributor block, which contained an exhaust hole for each cell. Connected to this distributor block was a rotating disk, with a single exhaust hole. The disk was secured with a nut and bolt to ensure that the disk would seal off the distributor block holes (See Figure 3). This disk was rotated by belt using a DC motor. The disk insured that the only cell that could exhaust was the one with its exhaust hole lined up with the exhaust hole on the rotating manifold disk. In this way it was insured that sequential exhausting would occur because only one cell could exhaust at a time. 
Once this device proved that the sequential exhaust concept did in fact work, a second device was built to allow more precise control and a broader range of exhaust timings. The second device used two manifolds purchased from Cole-Parmer. Each manifold contained three solenoid valves. This gave three exhausts for hydrogen and three exhausts for oxygen. See Figure 4. These valves were controlled by a Motorola HC-11 EVBU circuit board. Using the circuit board to control the timing of the exhaust allowed for more precise control and broader range of timings desired. It also allowed for the hydrogen and oxygen to be exhausted from the same cell at the same time. The circuit board was interfaced with a Windows-based computer.

\section{FUEL CELL CONTROL \& DATA ACQUISITION}

A potentiostat/gavlanostat system by Arbin Instruments (College Station, Texas, USA) was used to control the fuel cell operation and collect data. The main test used was a current staircase, where the current was staircased from low to high and the voltages at each current were measured. The program stepped the current from zero to nine amps in increments of one amp and then stepped back down to zero amps. The maximum current was limited by the Arbin system's capabilities to only handle ten Amps. The time for each step was five minutes on the staircase up to nine Amps and two minutes on the staircase back down. The staircase back down was used to insure that the cell performance was not changing. This test allowed for the creation of a polarization curve to compare performance. The temperature was not controlled in these experiments. Since the system is only undergoing a feasibility analysis, the fuel cell stack was allowed to heat itself.

Calculation of gas flow rates with the sequential exhaust system requires a different approach. Normally, a rotameter is used to observe the flow rates. However, since the 
exhausting mechanism causes pulsations of the flow rates, this method was insufficient. Since no other means was readily or economically available, a water displacement method was used. The stack exhaust was connected to a water bottle with an exit submerged in the water to allow the inflow of gas to displace water. The water was collected for thirty seconds and weighed to determine flow rate. The weight was then used to calculate an average flow rate for the exhaust. This method is not extremely accurate, but gives data good enough to show that the sequential exhausting makes efficient use of the fuel. The main inaccuracy suspected was a gradual pressure buildup in the water bottle, which would correspond to a compression of gas. However, it was found by monitoring the pressure in the bottle and using the maximum pressure to adjust the density of the gas that the error was less than 5\%. Therefore, it was deemed unnecessary to adjust for the changing pressure in the bottle.

For all fuel cell stack experiments performed, no additional water was added to the cells. In normal operation, the anode frequently dehydrates. To solve this problem, water is usually added to the anode side of the fuel cell. However, it was found that with the 25-micron thick membrane used in this study and appropriate gas flow rates, the back diffusion of water from the cathode was sufficient to keep the membrane well hydrated. This made it unnecessary to add water to the anode.

\section{RESULTS AND DISCUSSION}

\section{Gas Flow Control in a Two-Cell Stack}

As previously mentioned, the main goal of this research was to solve the gas flow distribution problem in a PEM Fuel Cell stack using an interdigitated flow field design. For this 
purpose one of the previously described sequential exhaust methods, the one employing a rotating device, was used. The method was applied first to a two-cell stack. The results are given in Figures 5 and 6. Figure 5 shows the overall power density of two methods, with and without sequential exhaust control. The fuel cells without sequential exhaust control were allowed to exhaust continuously. Figure 6 shows the polarization curve of each individual cell in the two arrangements. As suspected, without any flow control method, one of the cells performed well while the other died off. Cell 2 went into mass transport limitations almost immediately, as seen by the steep slope in the polarization curve. Due to reasons such as differences in morphological and wetting properties, as liquid water was generated in the gas diffusion layers of the cathodes of this fuel cell stack a resistance to flow developed in Cell 2, and gas preferentially flowed into Cell 1. The result was the lack of fuel and oxidant for Cell 2, yet it must produce the same current as Cell 1, due to the serial electrical connection. So, if water built up, the flow of gas decreased, which decreased the amount of water removed, yet the water production rate stayed the same. This self-defeating process quickly led to liquid water flooding. This mass transport problem promptly caused Cell 2 to die. As can be seen in Figure 5, the stack was only capable of generating a power density of $0.12 \mathrm{~W} / \mathrm{cm}^{2} /$ cell at these conditions when no control was used.

The results in Figure 5 and 6 clearly showed that the use of this sequential exhaust method dramatically improved the stack performance. Even though the two controlled cells performed better than the cells without the sequential exhaust control, individually their performances were not equal. We attributed this to that fact that even though the cells are sequentially exhausted, there was no guarantee that when the exhaust was open that the instantaneous flow rates would be the same because of the differences in the morphological and wetting properties of the MEAs used in these two cells. However, the sequential exhausting 
system performed as hypothesized by insuring that both cells received some gas, so neither of the cells went into mass transport limitations. Within these testing conditions, the fuel cell stack with the sequential exhaust system did not reach its peak power density, which is typically observed when the fuel cell potential is between $0.45 \mathrm{~V}$ and $0.5 \mathrm{~V}$. The maximum power density reached in this run was $0.33 \mathrm{~W} / \mathrm{cm}^{2} /$ cell at a current density of $0.55 \mathrm{~A} / \mathrm{cm}^{2}$, a dramatic increase over the performance of the stack without any flow control.

\section{Recovering from Flooding Study}

A final study performed on this two-cell stack was to examine its ability to recover from flooding by using a sequential exhausting device, in this case, the rotating device. Of the studies performed, the use of no control method was actually the last method examined. This was done because it was known from experience that the lack of control would cause flooding. The final test was whether or not good performance could be achieved after flooding had occurred. It could clearly be observed that after the previous run, Cell 2 was severely flooded. The test of success was whether the stack could now recover in the sequential exhausting device.

The sequential exhausting device was attached to the fuel cell stack that previous had no exhaust control device and another staircasing study was performed. The results of this study are presented in Figure 7. Figure 7 shows the average power density of the stack in terms of $\mathrm{W} / \mathrm{cm}^{2} /$ cell for four staircases performed with sequential exhausting after Cell 2 was previously flooded. When these results are compared to the one shown in Figure 5 it is clearly seen that each staircase consistently improved over the previous one. The sequential exhausting indeed allowed the stack to recover from flooded conditions even while operating at a high current density. It is significant that it was not necessary to stay at a low current density to allow Cell 2 
to dry out (i.e., liquid water entrapped in Cell 2 to evaporate). By the fourth staircasing the performance of this two-cell stack was equal to that of the previous two-cell stack operating with a sequential exhausting device shown in Figure 5.

\section{Gas Flow Control in a Three-Cell Stack}

After successful operation was achieved with a two-cell stack, a three-cell stack was examined. For this study a new exhausting device was created. It was found from our two-cell stack study that there was very limited control available with the rotating disk exhausting device. The frequency of exhaust could be adjusted by adjusting the rotating speed of the rotor of sequential exhausting device. However, the time on exhaust, which was controlled by the sizes of the gas openings on the stator and rotor and the rotating speed of the device, could not be adjusted after the device was made. Over time, the seal was sometimes lost, and the lubricant would wear down, leading to a slower rate of rotation. There was also no easy way to collect the exhaust in order to measure flow rates. For these reasons, a new method of exhausting was created.

The new device was made using solenoid valves to control exhausting. As described earlier, this device consisted of a Motorola HC-11 EVBU circuit board, which was used to control the opening and closing rate of the solenoid valve manifolds. A controlling program was written to sequentially open and close each of the three valves. The two parameters used to control the exhausting were the open time and closed time. Open time represents the time, in seconds, that the valve would remain open. Closed time represents the time, in seconds, that all valves were shut. The device contained two manifolds that consisted of three inlets with control 
valves and one outlet each. One manifold was used for the cathode and the other for the anode. Each cell was set to exhaust both the anode and cathode at the same time.

The use of sequential exhausting was again compared against the use of no exhaust to confirm that the scale up to a three-cell stack was successfully achieved. In order to confirm this, four staircases were performed; two stairs without sequential exhausting followed by two staircases with sequential exhausting. The performance in terms of average power density per cell is given in Figure 8. The first two staircases clearly show that without exhaust control, operation at high power density is not possible. The two staircases show that the performance got much worse on the second staircase, again emphasizing inability of the cell to remove water once it has built up in the gas diffusion layers of the electrodes. The first staircase was only capable of achieving $0.33 \mathrm{~W} / \mathrm{cm}^{2}$. The second stair was worse with a maximum power density of only $0.26 \mathrm{~W} / \mathrm{cm}^{2}$. Neither of the staircases was able to achieve $1.0 \mathrm{~A} / \mathrm{cm}^{2}$. Figure 9 shows, by means of a polarization curve, that without exhaust control, Cell 3 quickly exhibited a mass transport limited trend. It can clearly be seen that this cell poor performance limited the performance of the entire stack.

Once the sequential exhausting device was turned on, the performance improved dramatically, as seen from stairs 3 and 4 in Figure 8 . The results show that the three-cell stack achieves the same power density as the two-cell stack seen previously in Figure 5, 0.5 $\mathrm{W} / \mathrm{cm}^{2} /$ cell. It was also observed that with this valve controlled exhausting device, the recovery was much faster than with the rotating device. With the rotating device, four staircases were required for the two-cell stack to recover its optimal performance as compared to the three-cell stack with the valve-controlled device which achieved good performance on the first staircase. 
The reason for this is not definitely known, but it is suspected that the longer exhaust time obtained with the valve mechanism provides more effective liquid water removal from the gas diffusion layers of the electrodes in the cells. The rotating device did not allow the operator to measure the exhaust flow rate. Although the pulsing observed in the rotameters did not allow an accurate measure of flow rate, it gave an idea of consistency. One can watch the spikes in the rotameters due to the exhausting. This method was used to gauge the equality of flow rate between each cell. Different magnitudes of spike should naturally suggest different flow rates. Contrary to the case with the rotating device, the exhaust flow rates could be determined when the valve mechanism was used. The stoichiometric hydrogen and oxygen flow rates measured for this study are given in the next section. In the following study we would investigate the effects valve open and close timing and the corresponding flow rates through each cell on the performance of a three-cell stack.

\section{Effect of Timing \& Flow Rates}

Once it was determined that the use of sequential exhausting did improve the performance of a PEM fuel cell stack, the next study was to examine the effect different valve timings had on the performance. In this study each cell was opened for $0.3 \mathrm{~s}$ and closed for $2.1 \mathrm{~s}$ in the first case, $3.6 \mathrm{~s}$ in the second and 4.1 second in the third case. The sequence for the first case is illustrated in Table I. Note that the open and close cycle shown in Table I was repeated continuously during the fuel cell stack experiment. Figure 10 shows the performance of the three-cell stack for these three timing cases. Clearly there is no significant difference in the range of valve timings studied. It should be noted that this study was done with pure hydrogen and oxygen, so there was no starvation effect. The only effect that should be a detriment to the fuel 
cell performance is the build up of liquid water in the gas diffusion layers. Since no effect is seen in this range of timings, it can be concluded that the build up of liquid water in the gas diffusion layers within these valve closed intervals is actually quite low.

It would be expected that the rate of exhaust will be much more important when the fuel cell is operated on air. Since air is only $20 \%$ oxygen, there will be a build up of nitrogen when the cell is not exhausting. Since the oxygen will react, but the nitrogen will not, there will be a sharp decrease in the concentration of oxygen, which will have an effect on the current. The results for air operation will be presented in a future paper.

Next, the effect of sequential exhausting was used to examine the stoichiometric benefits. This was accomplished by using the exhaust gas to displace water. The water was collected over a 30 second period and used to estimate the average flow rate. It was found that benefits were very significant. As can be seen in Table II, at $1.0 \mathrm{~A} / \mathrm{cm}^{2}$ the stoichiometric flow rate of hydrogen was 1.04. This means only four percent of the gas was not consumed. This is a significant improvement over continuous exhausting operation. As was seen in the single cell operation, which was continuous, stoichiometric flow rates of up to 2.5 were used at $1.0 \mathrm{~A} / \mathrm{cm}^{2}$. This will have a significant effect on fuel efficiency, as less than $5 \%$ of the fuel is exhausted with sequential exhausting and up to $60 \%$ is exhausted in continuous operation. Even if the exhausted fuel is recycled, it will still represent a parasitic loss to the entire system, since it will require some sort of pumping to re-circulate the exhausted fuel. Similarly, the oxygen flow rates were greatly reduced by the use of this sequential exhausting system. At $1.0 \mathrm{~A} / \mathrm{cm}^{2}$, the oxygen flow rate was 1.13 times the stoichiometric flow rate with sequential exhaust versus 2.0 without. Note that the hydrogen and oxygen stoichiometric flow rates could be adjusted at different current 
densities by adjusting the valve closed and opened intervals to get optimal fuel and oxidant utilization.

\section{CONCLUSIONS \& RECOMMENDATIONS}

It was shown that ensuring gas flow to each cell solves the gas management problem of an interdigitated PEM fuel cell stack. Two sequential exhausting devices were tested, one based on a rotating device and another using electromechanical valves. Both showed dramatic improvement in performance associated with equalization of flow rate. Clearly the use of sequential exhausting and an interdigitated flowfield design are very promising methods for improving PEM fuel cell stack performance.

However, further work needs to be performed. The most obvious missing result is the performance with air as the cathode fuel, instead of pure oxygen. The use of air is very important since it represents the real life operating conditions. Since air is free, it will be used as the fuel instead of pure oxygen for terrestrial use. The most obvious result of using air is the decrease in performance due to lower oxygen concentration. The use of air also entails different operating conditions. When interdigitated flow fields are used, the air is forced to flow through the backing layer. Since for the same equivalent stoichiometric flow rate air must be delivered at five times the rate of oxygen, the water removal rates will be changed so the important water management parameters must be changed.

Finally, even though no results are given here we expect the sequential exhausting system to have similar effects on PEM fuel cell stacks using conventional or serpentine flow fields. These results will be presented in a future paper. 


\section{ACKNOWLEDGEMENTS}

The authors would like to thank Mr. Ed Atchison for helping with the development of the circuit board and software to control of the electromechanical valves used in the sequential exhausting system.

\section{REFERENCES}

1. Kordesh, K., and Simader, G., Fuel Cells and Their Applications, p. 44, Weinheim, VCH, (1996).

2. Shimpson Gottesfeld and Tom A. Zawodzinski, "Polymer Electrolyte Fuel Cells," in Advances in Electrochemical Science and Engineering, R. C. Alkire, H. Gerischer, D. Kolb, and C. Tobias, Eds., Vol. 5, Wiley-VCH, New York, pp. 197-301, 1997.

3. David Wood, III, Jung S. Yi and Trung V. Nguyen, Electrochimica Acta, 43, 3795-3809 (1998).

4. Mack W. Knobbe, “Gas and Water Management in a Proton Exchange Membrane Fuel Cell Stack,” M.S. Thesis, University of Kansas, Lawrence, Kansas, USA, 2000.

5. TVN Systems, Inc., Lawrence, Kansas 66047, USA.

6. Trung Van Nguyen, "Methodology for Supply of Reactant Fluids to and Purging of Product and Inert Fluids from Cells of Fuel Cell Stack,” U.S. Patent No. 9,552,419.

7. Trung V. Nguyen, “A Gas Distributor Design for Proton Exchange Membrane Fuel Cells,” J. Electrochem. Society, 143, L103-L105 (1996). 


\section{List of Tables}

1. Valve Close and Open Sequence for the 0.3 s Opened and 2.1 s Closed Case.

2. Gas Stoichiometric Flow Rates Achieved with Sequential Exhausting at Various Current and Power Densities for the 0.3 s-Opened and 4.1 s-Closed case .

\section{List of Figures}

1. Processes of Polymer Electrolyte Fuel Cell

2. Fuel Cell Stack with Parallel Gas Feed and Exhaust.

3. Fuel Cell Stack with Sequential Exhaust System Employing a Rotating Device.

4. Fuel Cell Stack with Sequential Exhaust System Using Electromechanical Devices.

5. Power Density Comparison of a Two-Cell Stack Operating With and Without Sequential Exhaust Control. Cell temperature $\approx 35^{\circ}-40^{\circ} \mathrm{C}, \mathrm{H}_{2}$ flow rate $=1.5 \mathrm{~A} / \mathrm{cm} 2$ equivalent, $\mathrm{O}_{2}$ flow rate $=2.0 \mathrm{~A} / \mathrm{cm} 2$ equivalent.

6. Polarization Curve Comparison of a Two-Cell Stack Operating With and Without Sequential Exhaust Control. Cell temperature $\approx 35^{\circ}-40^{\circ} \mathrm{C}, \mathrm{H}_{2}$ flow rate $=1.5 \mathrm{~A} / \mathrm{cm} 2$ equivalent, $\mathrm{O}_{2}$ flow rate $=2.0 \mathrm{~A} / \mathrm{cm} 2$ equivalent.

7. Recovery of a Two-Cell Stack from Flooded Conditions by Using a Sequential Exhausting Device. Cell temperature $\approx 35^{\circ}-40^{\circ} \mathrm{C}, \mathrm{H}_{2}$ flow rate $=1.5 \mathrm{~A} / \mathrm{cm} 2$ equivalent, $\mathrm{O}_{2}$ flow rate $=2.0 \mathrm{~A} / \mathrm{cm} 2$ equivalent.

8. Power Density Comparison of a Three-Cell Stack Operating With and Without Sequential Exhaust Control. Cell temperature $\approx 35^{\circ}-40^{\circ} \mathrm{C}$, for $\mathrm{H}_{2}$ and $\mathrm{O}_{2}$ flow rates see Table I.

9. Polarization Curve Comparison of a Three-Cell Stack Operating With and Without Sequential Exhaust Control. Cell temperature $\approx 35^{\circ}-40^{\circ} \mathrm{C}$, for $\mathrm{H}_{2}$ and $\mathrm{O}_{2}$ flow rates see Table I.

10. The Effect of Varied Valve Closed Time Intervals on the Performance of a Three-Cell Stack. Time Open $=0.3 \mathrm{~s}$. 
Table I. Valve Close and Open Sequence for the 0.3 s Opened and 2.1 s Closed Case.

\begin{tabular}{|c|c|c|c|c|c|}
\hline Cycle & Time (s) & Duration (s) & Cell 1 & Cell 2 & Cell 3 \\
\hline 1 & $0.0-0.5$ & $0.5 \mathrm{~s}$ & Closed & Closed & Closed \\
\hline 1 & $0.5-0.8$ & $0.3 \mathrm{~s}$ & Opened & Closed & Closed \\
\hline 1 & $0.8-1.3$ & $0.5 \mathrm{~s}$ & Closed & Closed & Closed \\
\hline 1 & $1.3-1.6$ & $0.3 \mathrm{~s}$ & Closed & Opened & Closed \\
\hline 1 & $1.6-2.1$ & $0.5 \mathrm{~s}$ & Closed & Closed & Closed \\
\hline 1 & $2.1-2.4$ & $0.3 \mathrm{~s}$ & Closed & Closed & Opened \\
\hline 2 & $2.4-2.9$ & $0.5 \mathrm{~s}$ & Closed & Closed & Closed \\
\hline 2 & $2.9-3.2$ & $0.3 \mathrm{~s}$ & Opened & Closed & Closed \\
\hline 2 & $3.2-3.7$ & $0.5 \mathrm{~s}$ & Closed & Closed & Closed \\
\hline 2 & $3.7-4.0$ & $0.3 \mathrm{~s}$ & Closed & Opened & Closed \\
\hline 2 & $4.0-4.5$ & $0.5 \mathrm{~s}$ & Closed & Closed & Closed \\
\hline 2 & $4.5-4.8$ & $0.3 \mathrm{~s}$ & Closed & Closed & Opened \\
\hline
\end{tabular}


Table II. Gas Stoichiometric Flow Rates Achieved with Sequential Exhausting at Various Current and Power Densities for the $0.3 \mathrm{~s}$-Opened and $4.1 \mathrm{~s}$-Closed case.

\begin{tabular}{|c|c|c|c|}
\hline $\begin{array}{c}\text { Current Density } \\
\left(\mathrm{A} / \mathrm{cm}^{\wedge} 2\right)\end{array}$ & $\begin{array}{c}\text { Power Density } \\
\left(\mathrm{W} / \mathrm{cm}^{\wedge} 2 / \mathrm{ce} l\right)\end{array}$ & H2 Stoich & O2 Stoich \\
\hline 0.33 & 0.23 & 1.25 & 1.79 \\
\hline 0.44 & 0.30 & 1.15 & 1.58 \\
\hline 0.56 & 0.36 & 1.14 & 1.43 \\
\hline 0.67 & 0.41 & 1.09 & 1.34 \\
\hline 0.78 & 0.47 & 1.06 & 1.28 \\
\hline 0.89 & 0.52 & 1.07 & 1.23 \\
\hline 1.00 & 0.56 & 1.04 & 1.13 \\
\hline
\end{tabular}




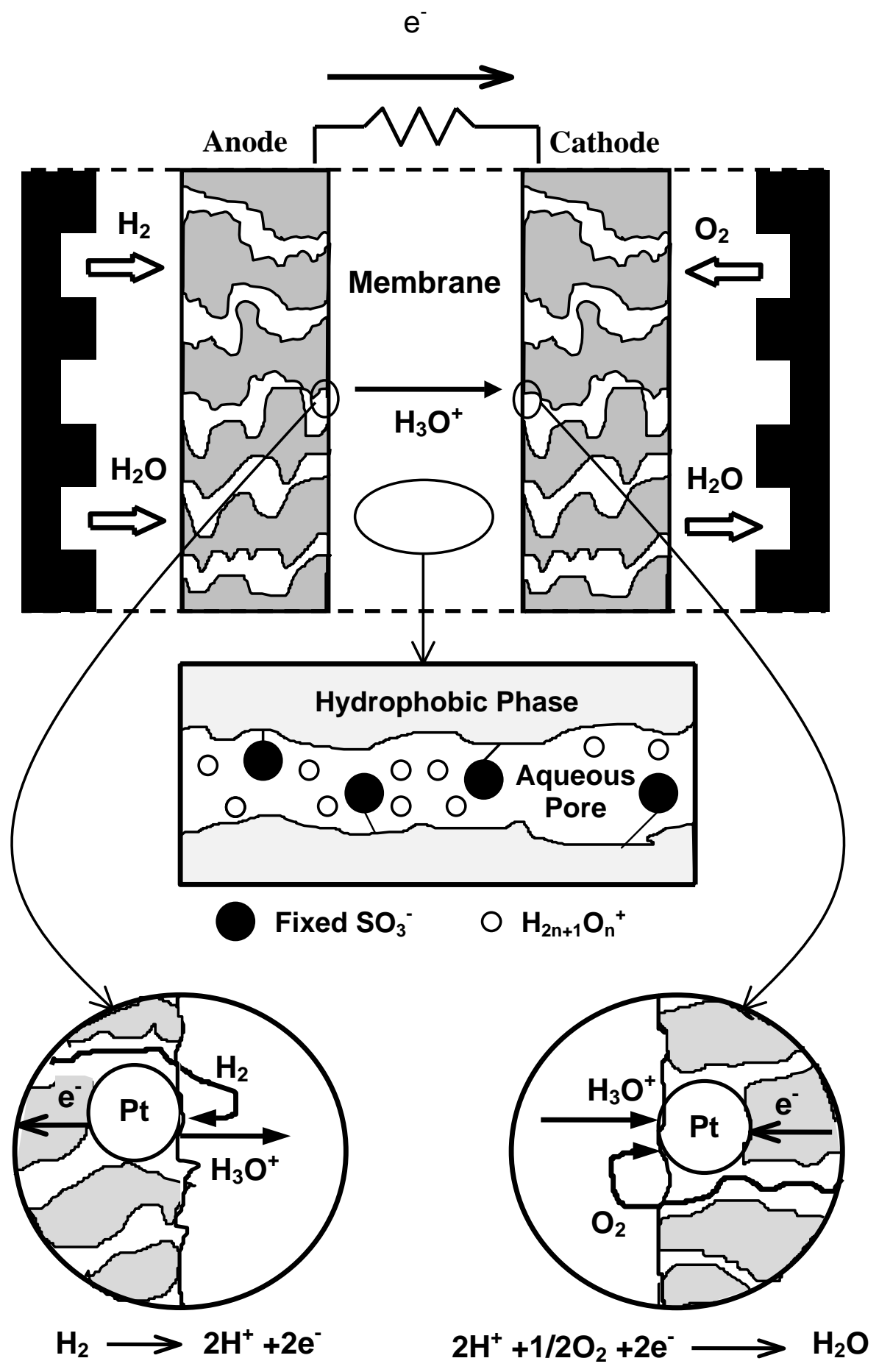

Figure 1. Processes of Polymer Electrolyte Fuel Cell 


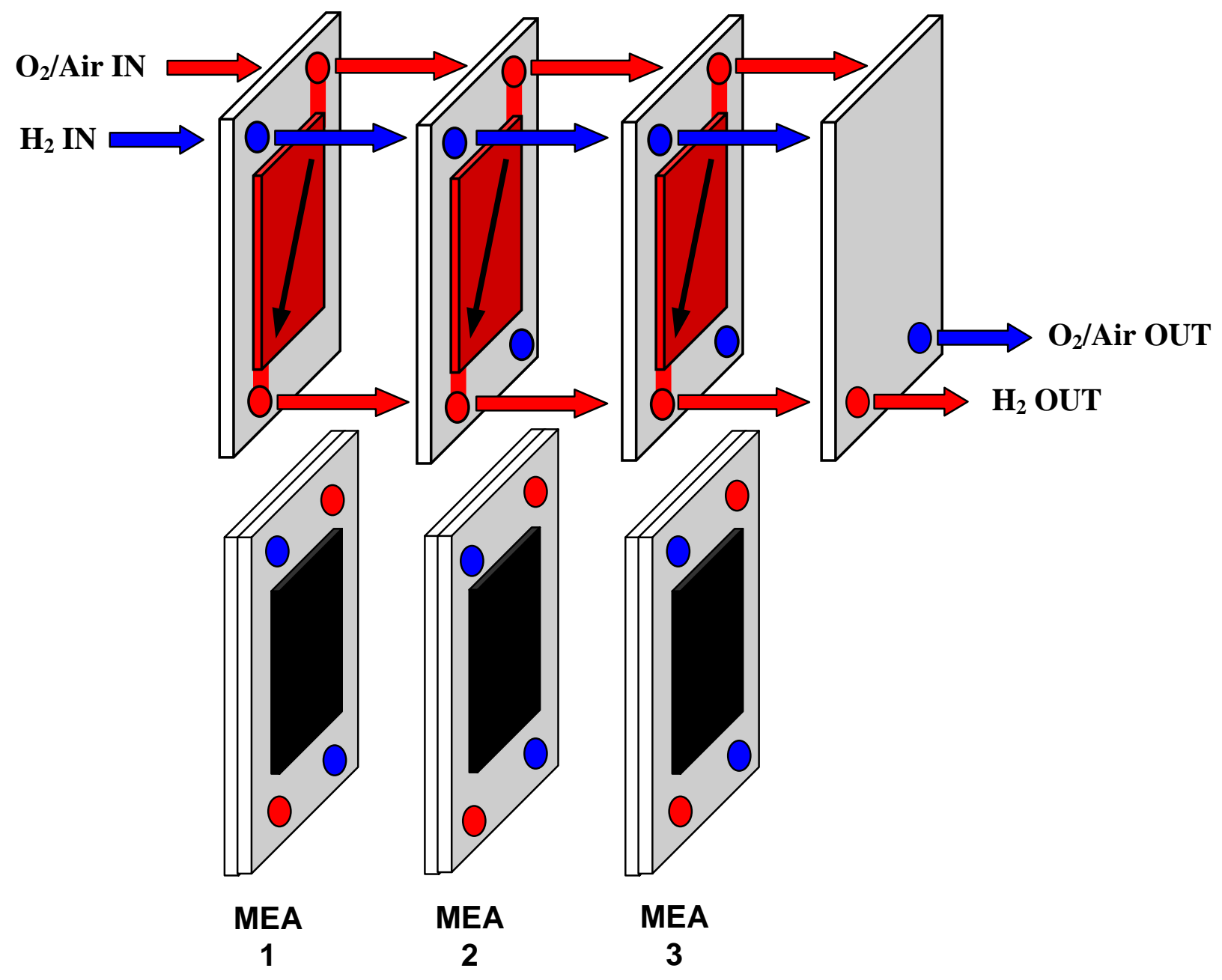

Figure 2. Fuel Cell Stack with Parallel Gas Feed and Exhaust. 


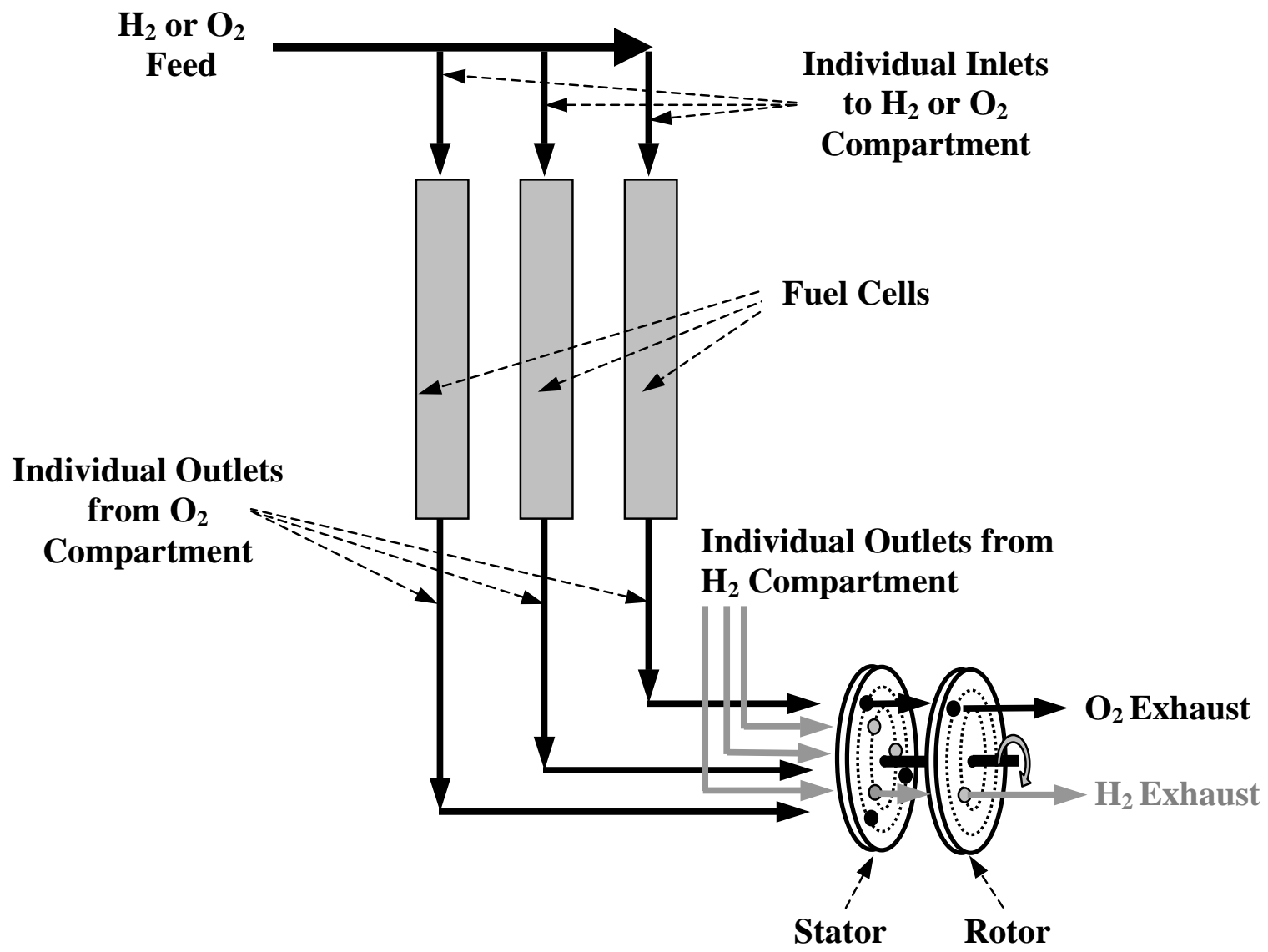

Figure 3. Fuel Cell Stack with Sequential Exhaust System Employing a Rotating Device. 


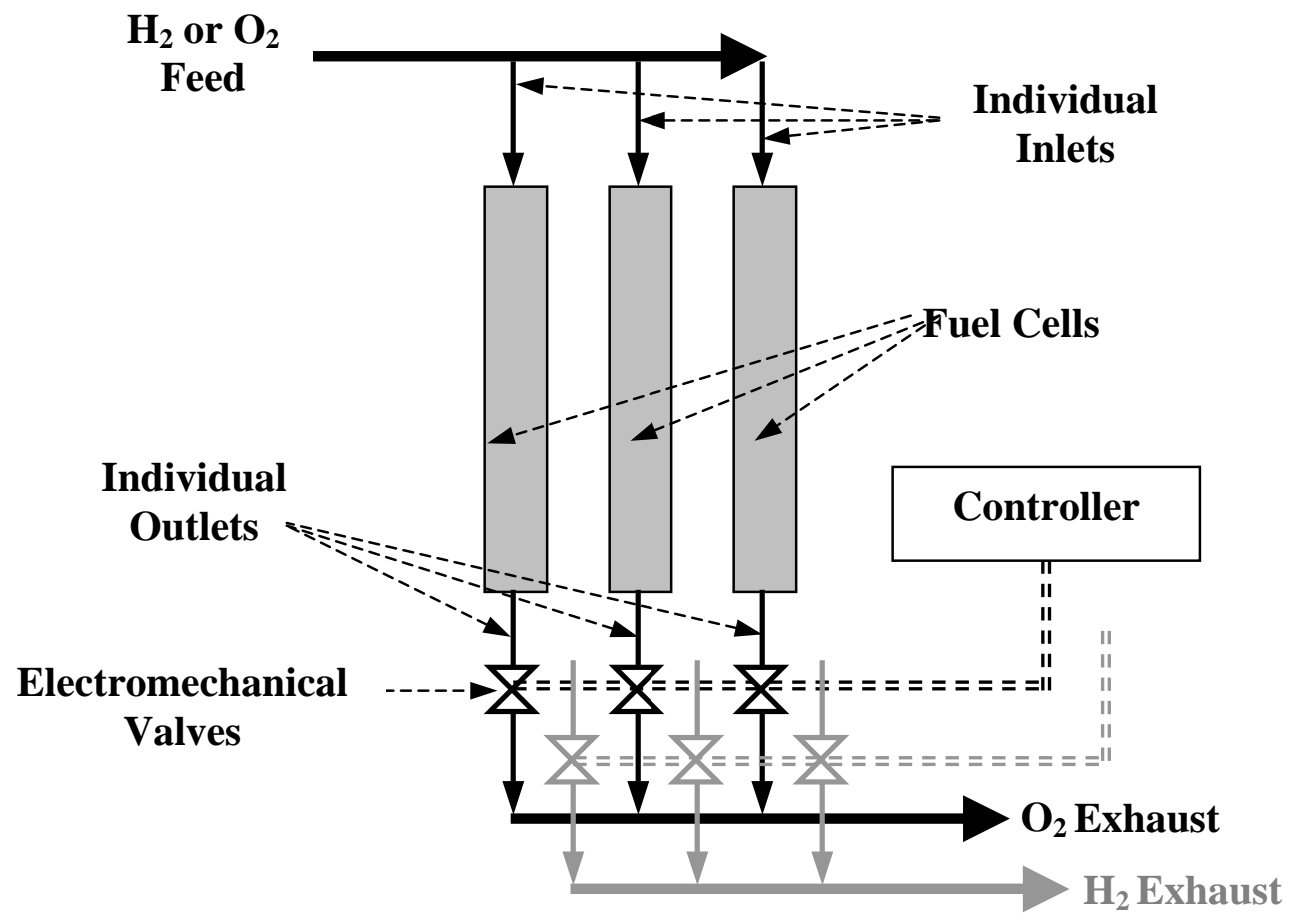

Figure 4. Fuel Cell Stack with Sequential Exhaust System Using Electromechanical Devices. 


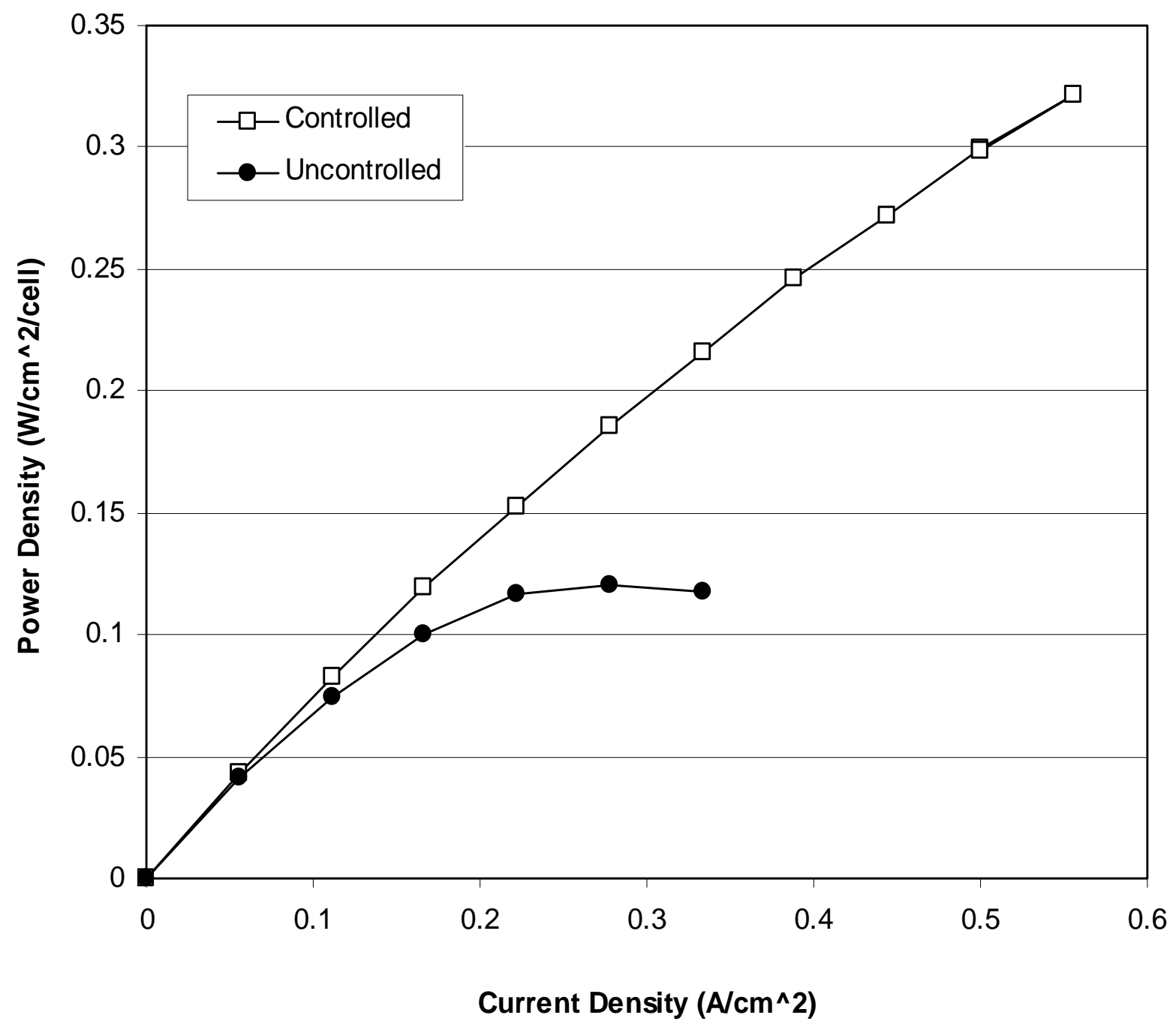

Figure 5. Power Density Comparison of a Two-Cell Stack Operating With and Without Sequential Exhaust Control. Cell temperature $\approx 35^{\circ}-40^{\circ} \mathrm{C}, \mathrm{H}_{2}$ flow rate $=$ $1.5 \mathrm{~A} / \mathrm{cm} 2$ equivalent, $\mathrm{O}_{2}$ flow rate $=2.0 \mathrm{~A} / \mathrm{cm} 2$ equivalent. 


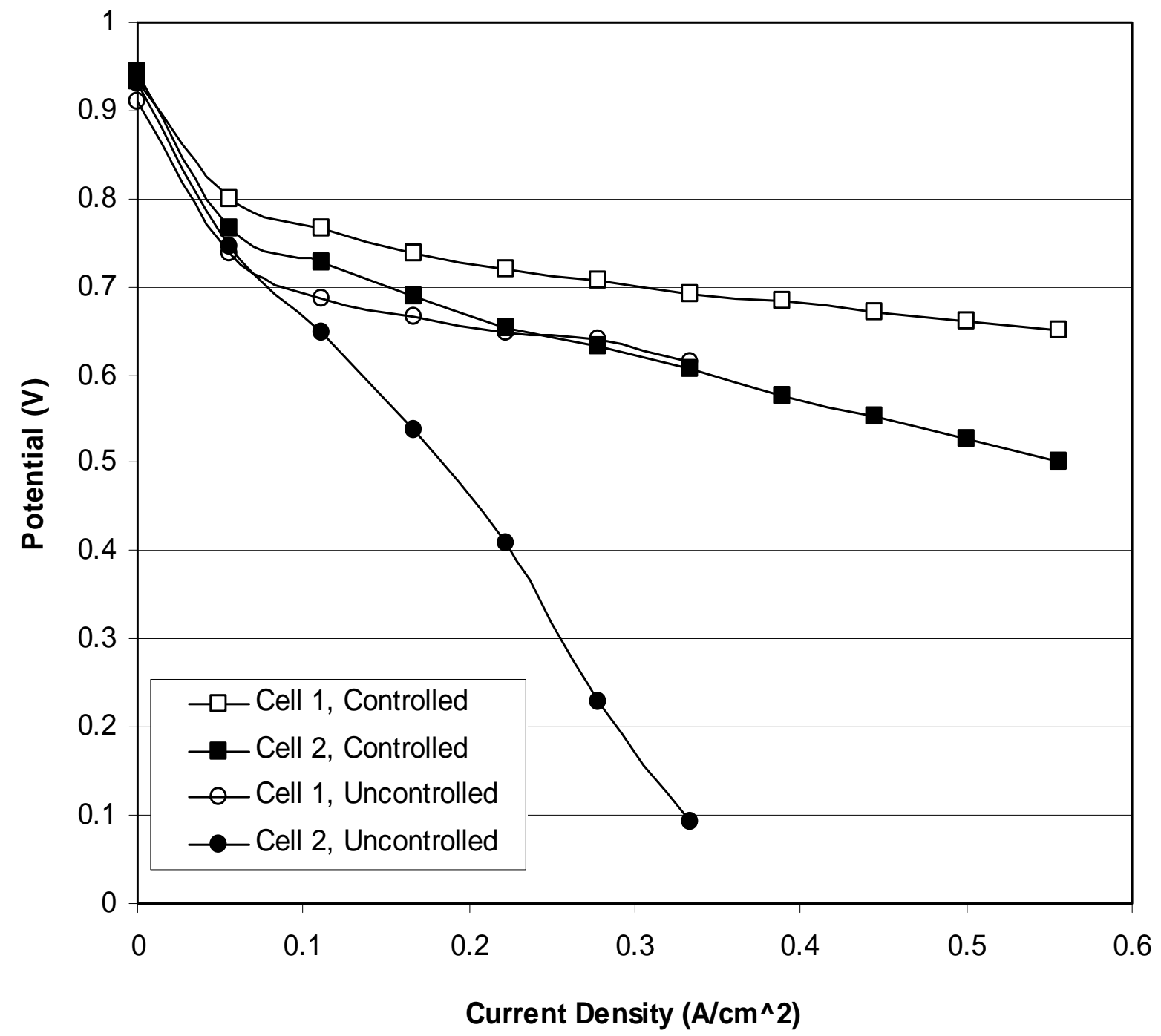

Figure 6. Polarization Curve Comparison of a Two-Cell Stack Operating With and Without Sequential Exhaust Control. Cell temperature $\approx 35^{\circ}-40^{\circ} \mathrm{C}, \mathrm{H}_{2}$ flow rate $=1.5 \mathrm{~A} / \mathrm{cm} 2$ equivalent, $\mathrm{O}_{2}$ flow rate $=2.0 \mathrm{~A} / \mathrm{cm} 2$ equivalent. 


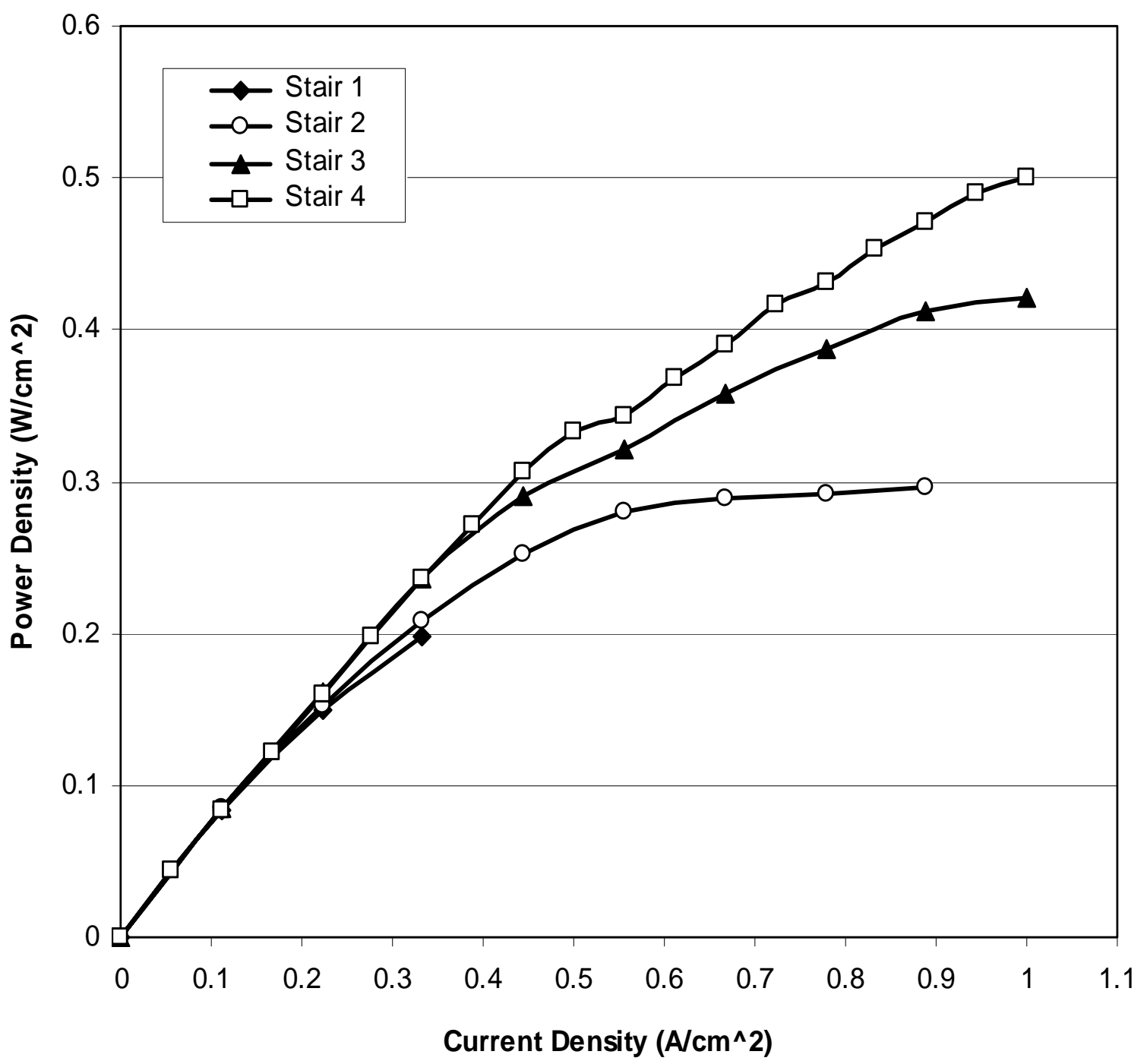

Figure 7. Recovery of a Two-Cell Stack from Flooded Conditions by Using a Sequential Exhausting Device. Cell temperature $\approx 35^{\circ}-40^{\circ} \mathrm{C}, \mathrm{H}_{2}$ flow rate $=1.5 \mathrm{~A} / \mathrm{cm} 2$ equivalent, $\mathrm{O}_{2}$ flow rate $=2.0 \mathrm{~A} / \mathrm{cm} 2$ equivalent. 


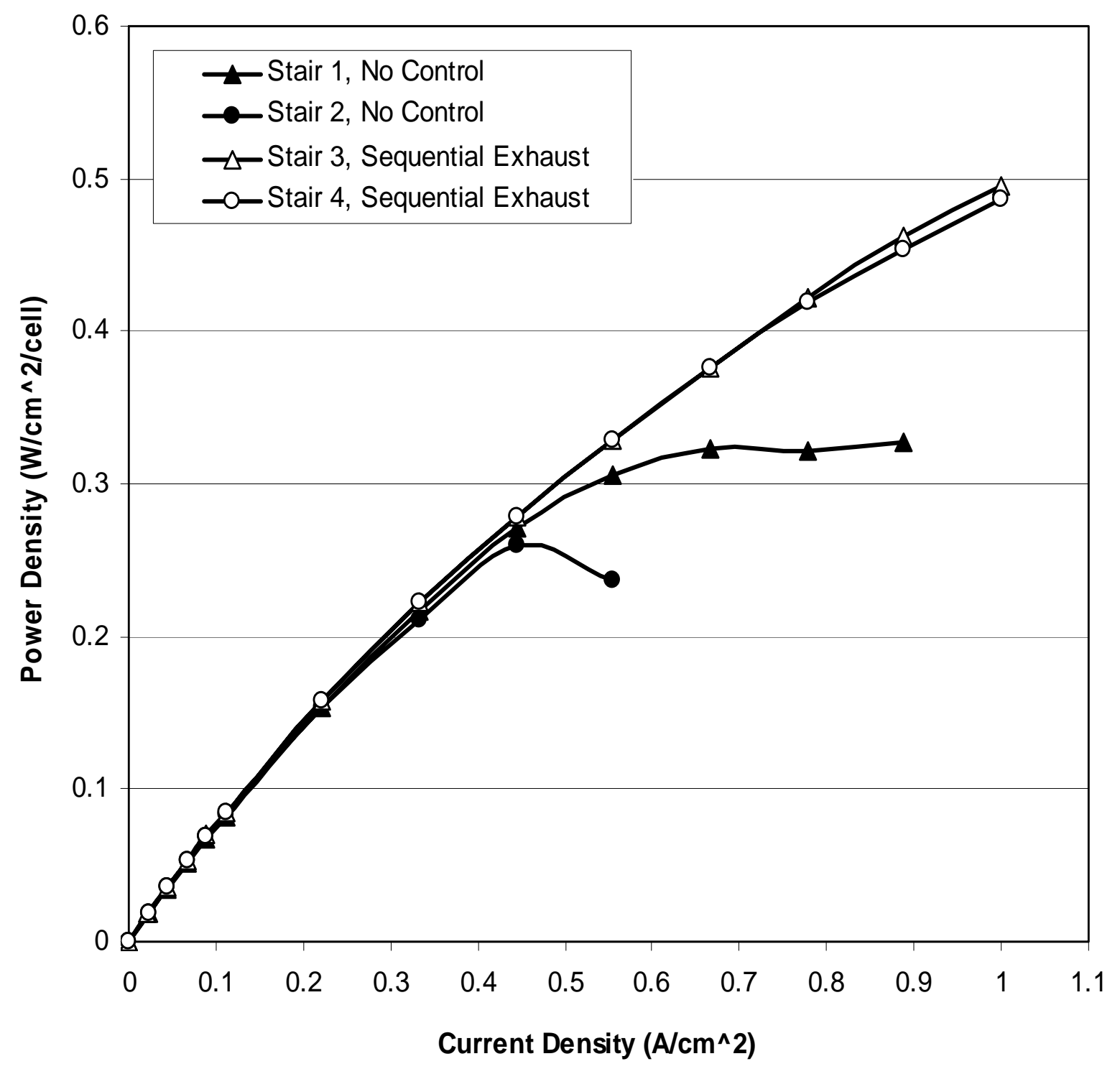

Figure 8. Power Density Comparison of a Three-Cell Stack Operating With and Without Sequential Exhaust Control. Cell temperature $\approx 35^{\circ}-40^{\circ} \mathrm{C}$, for $\mathrm{H}_{2}$ and $\mathrm{O}_{2}$ flow rates see Table $\mathrm{I}$. 


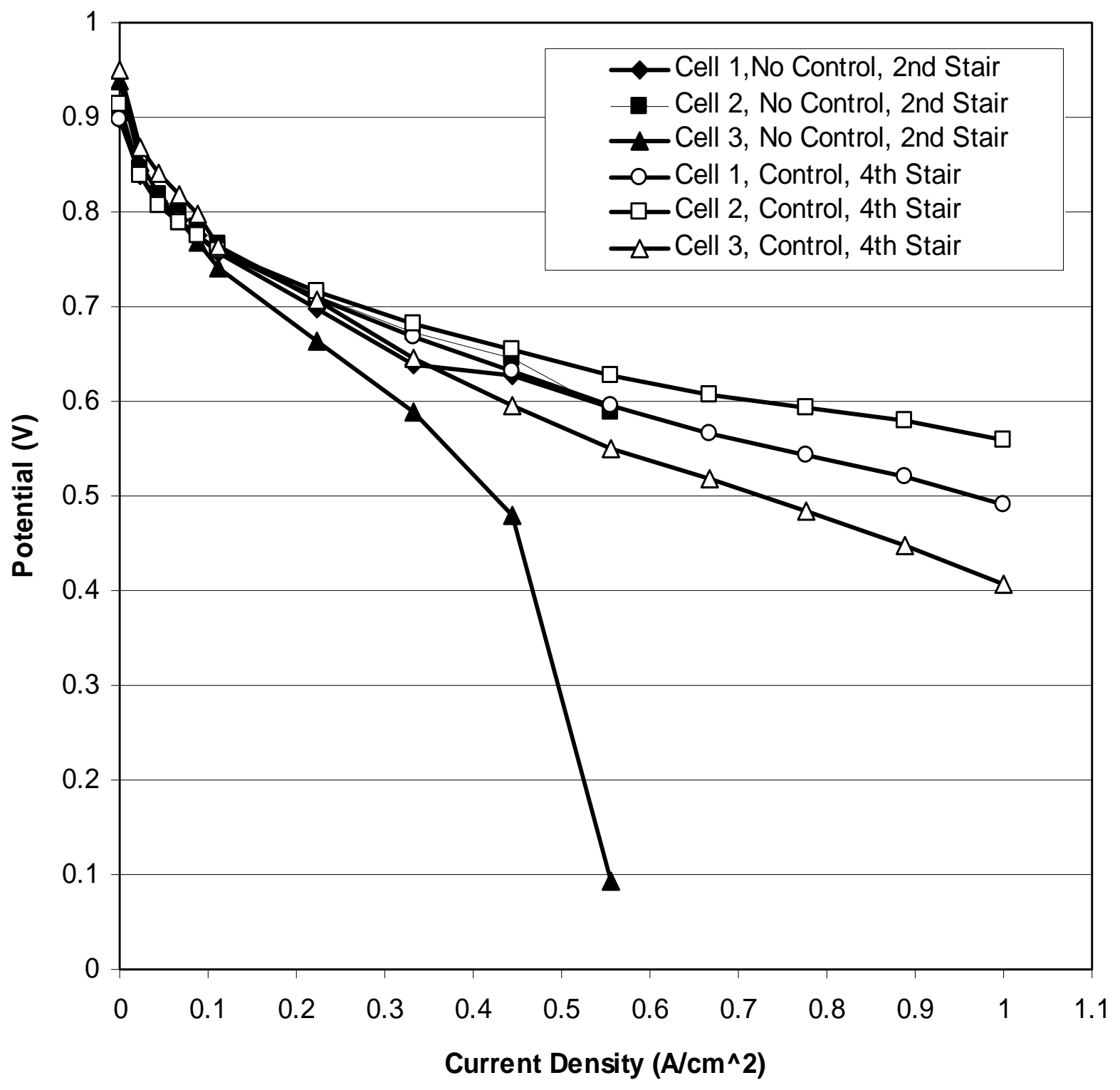

Figure 9. Polarization Curve Comparison of a Three-Cell Stack Operating With and Without Sequential Exhaust Control. Cell temperature $\approx 35^{\circ}-40^{\circ} \mathrm{C}$, for $\mathrm{H}_{2}$ and $\mathrm{O}_{2}$ flow rates see Table I. 


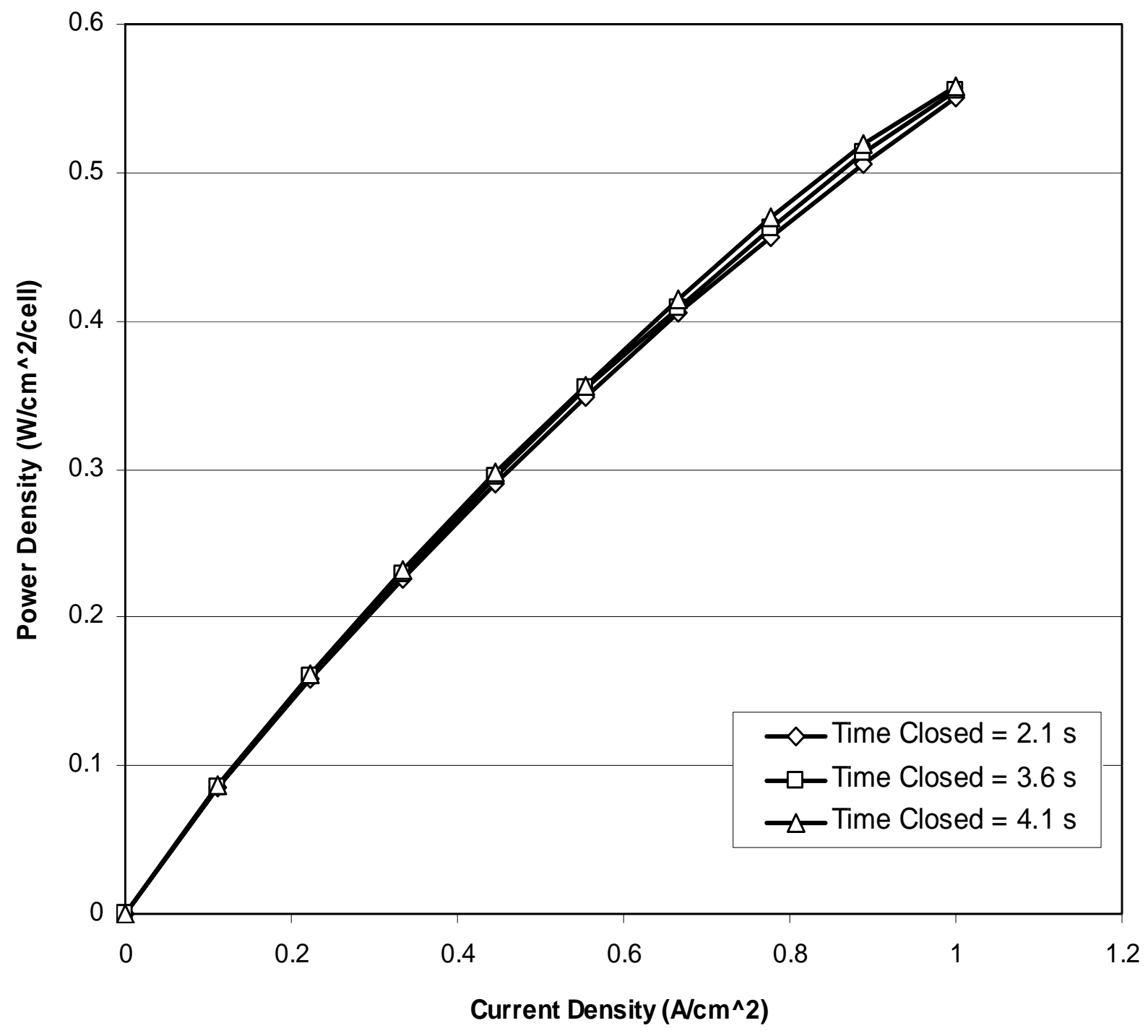

Figure 10. The Effect of Varied Valve Closed Time Intervals on the Performance of a Three-Cell Stack. Time Open $=0.3 \mathrm{~s}$. 